\section{OP12 THE IMPACT OF PARTICIPANT-LED 'ASSETS' DURING ADOLESCENCE OF EARLY ADULT HEALTH AND WELL- BEING IN THE UK: LONGITUDINAL ANALYSIS AND WELL-BEING TRAJECTORIES USING THE 'NEXT STEPS' DATASET}

${ }^{1} \mathrm{JA}$ McGowan* ${ }^{2} \mathrm{~A}$ Hagell, ${ }^{2} \mathrm{E}$ Rigby, ${ }^{2} \mathrm{R}$ Shah, ${ }^{1} \mathrm{M}$ Heyes, ${ }^{3} \mathrm{D}$ Hargreaves, ${ }^{1} \mathrm{R}$ Viner. ${ }^{1}$ Institute of Child Health, University College London, London, UK; ${ }^{2}$ Association for Young People's Health, London, UK; ${ }^{3}$ Imperial College London, London, UK

\subsection{6/jech-2019-SSMabstracts.12}

Background While employment and education rates have been extensively studied, little is known about how general wellbeing through early-late adolescence impacts well-being into adulthood. Utilising participant-led research, we mapped the presence and trajectories of 'assets' identified by young people (YP) as important during their adolescence to 'success' in early adulthood.

Methods YP identified four 'assets': 'appropriate skills', 'social capital', 'financial support' and 'emotional support', which were mapped across early(T1: age 13-15), $\operatorname{mid}(\mathrm{T} 2$ : $16-17)$, and late(T3: 18-20) adolescence. Four adult (age 25-26) outcomes were also identified: 'suitable/rewarding work', 'satisfactory housing', 'good relationships', and 'healthy habits'. The presence of these were identified using binary measures, developed from the 'Next Steps' dataset - a yearly longitudinal study following English individuals born in 1989/1990 $(\mathrm{N}=15,770)$. Trajectories were categorised as an asset being 'stable high', 'stable low', 'late rising' (T3), 'early rising' (T2), 'late falling', 'early falling', and 'unstable'.

Results A complete case analysis was performed. Data was weighted using the standard LSYPE weightings. Assets were reported by $90 \%$ (emotional support) - 20\% (confidence and connections) of young people, and generally decreased in prevalence over adolescence $(\mathrm{ps}<0.001)$. At age 25 , Just over half of YP reported 'satisfactory housing' $(53.8 \%, \mathrm{SE}=0.8)$ or 'suitable/rewarding work' (59.9\%, $\mathrm{SE}=0.7)$. The majority reported 'good relationships' $(87.7 \%, \mathrm{SE}=0.5)$ and 'healthy habits' $(74.3 \%, \mathrm{SE}=0.6)$.

Using regression analyses adjusted for sex and ethnicity, we identified that attaining 'suitable/rewarding work' at age 25/26 was associated with the presence of 'skills' (T1:Coef $=1.36$, 95\% CI=1.18-1.58; T2: $\operatorname{Coef}=1.30,95 \% \mathrm{CI}=1.13-1.49$ ); T3: Coef $=1.29,95 \% \mathrm{CI}=1.10-1.51, \mathrm{ps}<0.001$ ) and 'financial support' $(\mathrm{T} 1:$ Coef $=1.21,95 \% \mathrm{CI}=1.04-1.41, \mathrm{~T} 2: \mathrm{Coef}=1.27,95 \%$ $\mathrm{CI}=1.05-1.52 ; \mathrm{T} 3: \mathrm{Coef}=1.21,95 \% \mathrm{CI}=1.05-1.39 ; \mathrm{ps}=0.01$ ) at all adolescent age-bands, and 'confidence and connections' at ages 16-20. 'Satisfactory housing' was associated with skills, confidence \& connections, and financial support at all timepoints. 'Good relationships' was associated with all assets, except financial support at T3. 'Healthy habits' was not consistently related to any asset. Regardless of outcome, the benefits of the asset trajectories remained the same: compared to 'stable low' trajectories, 'stable high' trajectories showed the largest benefit across all assets. For 'skills', any trajectory other than 'stable low' had a statistically significant positive adult outcome (ps<0.002). For 'confidence and connections' and 'financial support', 'early rising', 'stable high', and 'late falling' were consistently related with a positive outcome ( $\mathrm{ps}<0.01$ and $<0.03$ ). Conclusion The assets available to adolescents impact their young adult outcomes across distinct pathways, but not all assets are commonly available to YP. The stability of these assets across adolescence is of particular importance to adult outcomes, as is their presence in early-mid adolescence.

\section{OP13 MORTALITY RISK AMONGST VERY LOW BIRTH WEIGHT INFANTS BORN IN THE REPUBLIC OF IRELAND}

${ }^{1}$ P Corcoran*, 'S Leitao, ${ }^{2}$ A Twomey, ${ }^{3}$ BP Murphy. ${ }^{1}$ National Perinatal Epid. Centre, NPEC Dept. Obs and Gynae, UCC, Cork, Ireland; ${ }^{2}$ Consultant Neonatologist, National Maternity Hospita, Dublin, Ireland; ${ }^{3}$ Consultant Neonatologist, Cork University Maternity Hospital, South/Southwest Hospital Group, Cork, Ireland

10.1136/jech-2019-SSMabstracts. 13

Background Globally, there are approximately six million deaths of children under 5 years of age each year, the leading cause of which is preterm birth complications. Very preterm infants are at especially high risk of mortality. The Vermont Oxford Network (VON) is a non-profit voluntary collaboration of health care professionals from nearly 1000 neonatal intensive care units around the world and it maintains a database of information regarding the care and outcomes of highrisk newborn infants.

We aimed to use the VON data to assess whether very low birth weight (VLBW) infants born in Ireland in 2014-2016 had a higher than expected risk of death.

Methods Since 2014, all 19 neonatal units in Ireland have contributed data to the VON database on VLBW infants, defined as an infant who is born alive and whose birth weight is between 401 and 1500 grams OR whose gestational age is between 22 weeks 0 days and 29 weeks 6 days (inclusive). VON colleagues use multivariable logistic regression models to quantify the risk of mortality associated with a range of infant characteristics. We used coefficients from these regression models to calculate standardised mortality ratios (SMRs).

Results The VON database had data on 1,812 VLBW infants born in Ireland in 2014-2016, of which 1,765 were records from their hospital of birth. The mortality risk for these 1,765 infants was 1.17 times higher than expected, a statistically significant excess mortality (95\% CI: 1.05, 1.29). Infants born at 22-23 weeks had a 23\% higher mortality risk $(\mathrm{SMR}=1.23,95 \% \mathrm{CI}: 1.02,1.44)$ that was almost wholly due to the infants not administered resuscitation. Infants born at 24-27 weeks in a tertiary unit did not experience higher than expected mortality $(\mathrm{SMR}=1.01,95 \% \mathrm{CI}: 0.80,1.23)$ but those born in non-tertiary units had a $70 \%$ higher mortality risk $(\mathrm{SMR}=1.70,95 \% \mathrm{CI}: 1.25,2.15)$.

Conclusion These findings support the recommendations that resuscitation should be administered to all infants born at 23 weeks who present in favourable condition, i.e. without congenital anomaly, severely small for gestational age, severe hypoxia or severe infection. In line with the existing Model of Care for Neonatal Services in Ireland, infants born before reaching a gestational age of 28 weeks should ideally be delivered at a tertiary neonatal unit.

\section{OP14 WHAT MODERATES THE SCARRING EFFECT OF YOUTH UNEMPLOYMENT ON LATER LIFE MENTAL HEALTH?}

L Wright*, J Head, S Jivraj. Epidemiology and Public Health, University College London, London, UK

\subsection{6/jech-2019-SSMabstracts.14}

Background Close to half a million young people are currently unemployed in the UK. Several studies show that youth unemployment is associated with worse mental health in later life. Few have looked at whether this association is limited to certain groups or is pervasive across the population. Our study 